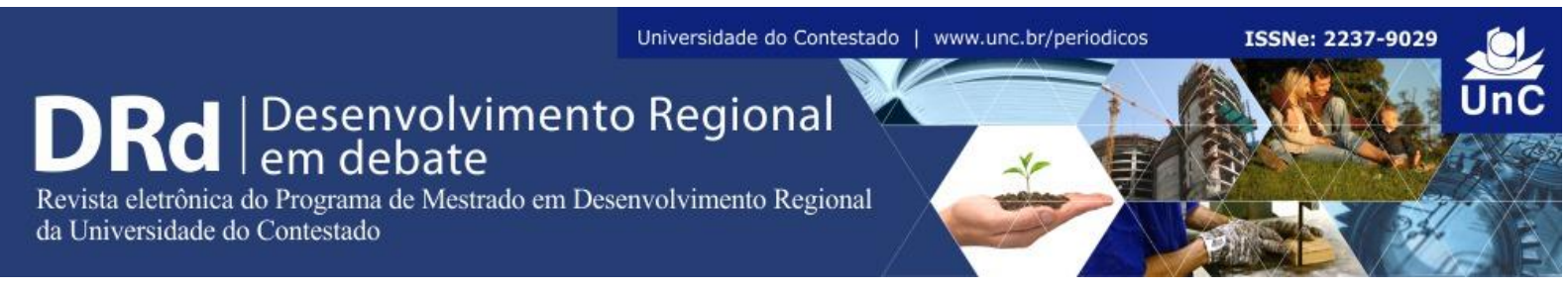

\title{
RENOVAR ECONOMÍAS URBANAS EN CRISIS: UN DEBATE ACTUAL SOBRE LA INNOVACIÓN ${ }^{1}$
}

Ricardo Mendez Gutierrez del Valle ${ }^{2}$

\section{RESUMEN}

Los estudios sobre innovación cuentan con amplio desarrollo en la geografía económica y los estudios sobre desarrollo de las últimas décadas, que ha dado lugar a una creciente diversificación de conceptos y teorías. En periodos de crisis como los vividos en los últimos años, la innovación resurge como estrategia necesaria para revitalizar las economías urbanas, pero también para lograr unas sociedades más inclusivas y unas ciudades más sostenibles y menos desiguales. El artículo plantea una reflexión teórica sobre la evolución de los estudios sobre innovación y recupera algunas ideas de especial interés desde la perspectiva de la resiliencia urbana. Analiza luego las propuestas para renovar las economías urbanas surgidas en España tras la profunda crisis del modelo de crecimiento y urbanización dominante desde finales del pasado siglo. También propone una línea de investigación aún poco desarrollada sobre economía alternativa, como realidad emergente en muchas ciudades como resultado de factores diversos y complementarios, que constituye un laboratorio de innovación social y organizativa.

Palabras clave: Innovación. Economías urbanas. Crisis. Economía alternativa.

\section{RENEW URBAN ECONOMIES IN CRISIS: A CURRENT DEBATE ON INNOVATION}

\begin{abstract}
Innovation studies have large development in economic geography and development studies in recent decades, and it has resulted in a growing diversification of concepts and theories. In times of crisis as experienced in recent years, innovation reemerges as a necessary strategy to revitalize urban economies, but also to achieve more inclusive societies and more sustainable and less unequal cities. The article is a theoretical reflection on the evolution of innovation studies and retrieves some ideas of particular interest from the perspective of urban resilience.
\end{abstract}

\footnotetext{
${ }^{1} \mathrm{El}$ artículo forma parte del proyecto de investigación sobre Espacios y prácticas económicas alternativas para la construcción de la resiliencia urbana, integrado en el Programa Estatal de Investigación, Desarrollo e Innovación Orientada a los Retos de la Sociedad, financiado por el Ministerio de Economía y Competitividad de España (CSO2015-65452-R MINECO-FEDER).

${ }^{2}$ Profesor de investigación en el Instituto de Economía, Geografía y Demografía del CSIC. Madrid (España). Email: ricardo.mendez@cchs.csic.es
}

DRd - Desenvolvimento Regional em debate (ISSNe 2237-9029)

v. 6, n. 3, p. 4-31, nov. 2016. 
Then analyzes the proposals to renew urban economies emerged in Spain after the deep crisis of the growth and urbanization model dominant since late last century. It also proposes a research on alternative economy as emerging reality in many cities, a result of various and complementary factors, which supposes a laboratory of social and organizational innovation.

Keywords: Innovation. Urban economies. Crisis. Alternative economy.

\section{INTRODUCCIÓN}

La innovación se ha convertido ya en una temática con cierta tradición en la geografía económica, así como en los estudios urbanos y regionales. Desde hace tres décadas son muy numerosas las publicaciones científicas o documentos oficiales que ponen creciente énfasis en la necesidad de construir economías regionales más basadas en la innovación y el conocimiento, así como ciudades que a lo anterior sumen mayor capacidad de responder a los retos en materia de cohesión social, segmentación espacial y sostenibilidad ambiental provocados por un proceso urbanizador dominado por la hegemonía de la racionalidad neoliberal (LAVAL; DARDOT, 2013).

En el plano discursivo, las demandas favorables a un mayor esfuerzo innovador se han generalizado hasta llegar a convertirse en un tópico social, pues son muchos los documentos oficiales de diferentes instituciones que aluden a la necesidad de aumentar la inversión que se le destina, densificar los sistemas de innovación, avanzar hacia una sociedad del conocimiento, promover el talento, o construir ciudades más inteligentes y creativas, referencias habituales en un tiempo de metáforas como el actual. Su traducción práctica en iniciativas y, más aún, en cuanto a resultados parece en cambio bastante heterogénea y mantiene abiertas las preguntas de investigación relativas a dónde surge la innovación y por qué, cuáles son los ambientes económicos, sociales e institucionales más favorables a su consolidación, qué formas de organización propician el aprendizaje colectivo, por qué vías se difunde el conocimiento y hasta qué punto es importante la proximidad, o qué políticas y a qué escala resultan más eficaces para su promoción. Eso justifica que la bibliografía científica que intenta responder tales cuestiones se haya mantenido plenamente vigente, aumentando su volumen, así como diversificando sus temáticas y métodos de investigación.

La profunda crisis sistémica padecida en los últimos años y el declive a que se enfrentan numerosas ciudades, que deben abordar estrategias de revitalización económica y regeneración social orientadas a lograr una revitalización de la actividad y del empleo, pero también evitar la reedición de los errores pasados promoviendo una economía y una urbanización más eficientes, ambientalmente sostenibles y que posibiliten mayor justicia social y espacial, vuelve a acentuar la urgencia de este tipo de respuestas pues, tal como recuerda Laville (2015, p. 166), “[...] en los periodos que se pueden calificar como periodos de crisis, la pérdida de aliento de los anteriores modos de acción pública incita a la búsqueda de nuevos paradigmas". Así pues, en esta fase de transición en que nos encontramos, entre el agotamiento de un modelo de crecimiento que se ha demostrado insostenible e injusto y la búsqueda de alternativas que aún resulta exploratoria e incierta, recuperar el debate sobre la aportación de la innovación y del conocimiento a la reconstrucción de las economías urbanas puede resultar relevante. Pero, para que ese debate sea realmente fructífero parece también

DRd - Desenvolvimento Regional em debate (ISSNe 2237-9029)

v. 6, n. 3, p. 4-31, nov. 2016. 
indispensable una breve reflexión sobre la gran cantidad de conceptos, ideas y prácticas aplicadas desde que la innovación reapareció en el ámbito de las ciencias sociales en los años ochenta del pasado siglo; un momento también de transición post-crisis en que se buscaban alternativas al régimen de acumulación fordista y a un modo de regulación keynesiano que parecían agotados.

En ese contexto, los objetivos y contenidos del artículo se organizan en cuatro pasos sucesivos, coincidentes con los epígrafes que estructuran el texto. Se trata, en primer lugar, de revisar los antecedentes relativos a la evolución de los conceptos y las teorías de la innovación en el ámbito de la geografía económica, porque cualquier propuesta actual es deudora de esa trayectoria, que condiciona nuestra manera de ver y también provoca cierto olvido de temáticas que en algunos casos pueden ser hoy de nuevo útiles para promover un debate renovado.

Tres décadas de investigación dejan unos resultados de enorme dimensión, variedad y complejidad. Pero entre ellos es posible seleccionar algunas ideas fundamentales, que resultan de especial utilidad para revisar el significado de la innovación y del conocimiento en los nuevos escenarios a que se enfrentan las economías urbanas. De eso trata el segundo apartado del texto, que destaca ciertos argumentos que luego se retoman para relacionarlos con algunas propuestas recientes para renovar las economías urbanas en los países de la periferia europea.

El tercer apartado hace una aproximación también muy selectiva a los rasgos básicos del modelo de crecimiento dominante en muchas ciudades españolas desde la última década del pasado siglo y hasta el estallido de su crisis en 2007. Tras recordar algunas de sus claves, se resumen las principales alternativas planteadas en los últimos años que comparten la necesidad de avanzar hacia un nuevo modelo productivo. Pese al distinto énfasis en cuanto a las actividades que pueden considerarse estratégicas para ese logro, existe en cambio bastante coincidencia en la importancia que conceden a la innovación como medio de lograr una mejora competitiva no basada en la simple reducción de costes y en el conocimiento como recurso fundamental para la modernización de las economías urbanas.

Finalmente, entre esas diversas opciones, el último apartado presta especial atención a aquellas iniciativas, prácticas y entidades que plantean objetivos alternativos a los hegemónicos, ya sea en el ámbito de la producción, el intercambio, el consumo o la financiación, al tiempo que priman las relaciones de proximidad entre sus participantes y muestran especial densidad en determinados espacios urbanos, a los que contribuyen a dotar de identidad. Su carácter emergente, su variada tipología y, sobre todo, el amplio conjunto de innovaciones sociales y organizativas que a menudo conllevan, son objeto de especial atención. Se pretende así proponer una mayor atención hacia un tipo de actividades cada vez más presentes y visibles en las áreas urbanas pero que están poco representadas en la investigación académica, a partir de la convicción sobre la necesidad de ampliar nuestra perspectiva pues "[...] estamos en un momento que requiere una serie de tácticas de choque de la imaginación, que desplacen el sentido común existente sedimentado y que abran la posibilidad a otras maneras de pensar" (MASSEY, 2012, p. 249). 


\section{INNOVACIÓN Y CONOCIMIENTO PARA EL DESARROLLO URBANO: EVOLUCIÓN DE UNA TEMÁTICA DE INVESTIGACIÓN}

En un contexto dominado por la aceleración y globalización de los procesos, la desregulación de los mercados y la mayor interdependencia espacial, junto al aumento del riesgo y la incertidumbre para un elevado número de territorios que se profundiza tras la última crisis capitalista, la capacidad de las ciudades para adaptarse a unos cambios constantes, renovar y revitalizar sus economías, regenerar un tejido social muy dañado por la creciente desigualdad y promover formas de urbanización más equilibradas y sostenibles se convierte en esencial. Por ese motivo, aumentar el stock de conocimientos, promover la innovación y estimular la producción o absorción de respuestas creativas vuelven a convertirse en claves para que las ciudades puedan explorar nuevos caminos de desarrollo, tanto en países y regiones centrales como también, hasta cierto punto, en ámbitos territoriales periféricos, pese a los frenos estructurales que en este caso limitan su potencial innovador (DALLABRIDA; FERNÁNDEZ, 2008).

Pese a que el concepto de innovación cuenta ya con una larga tradición académica desde que fue recuperado por una economía evolucionista inspirada en las ideas pioneras de Schumpeter o Veblen, el interés por comprender sus múltiples formas, identificar las razones que explican su desigual distribución sectorial y territorial o los canales por los que se difunde, observar sus consecuencias allí donde se implanta, así como proponer políticas públicas para promoverla y difundirla, continúa suscitando numerosas investigaciones y un innegable interés social. Por ese motivo, replantear hoy el valor de la innovación para el desarrollo urbano en el nuevo escenario económico exige, al menos, un repaso sintético del recorrido que ha tenido esta temática en las tres últimas décadas para seleccionar algunas aportaciones que justifiquen y sirvan de marco a cualquier propuesta posterior. La Figura 1 resume los principales hitos que han jalonado ese recorrido y algunos de los autores que mejor identifican cada uno de ellos, reuniendo tanto aquellas aportaciones planteadas, sobre todo, a escala regional junto a otras específicas a escala urbana. 
Figura 1 - Evolución de conceptos y teorías en los estudios sobre innovación y conocimiento.

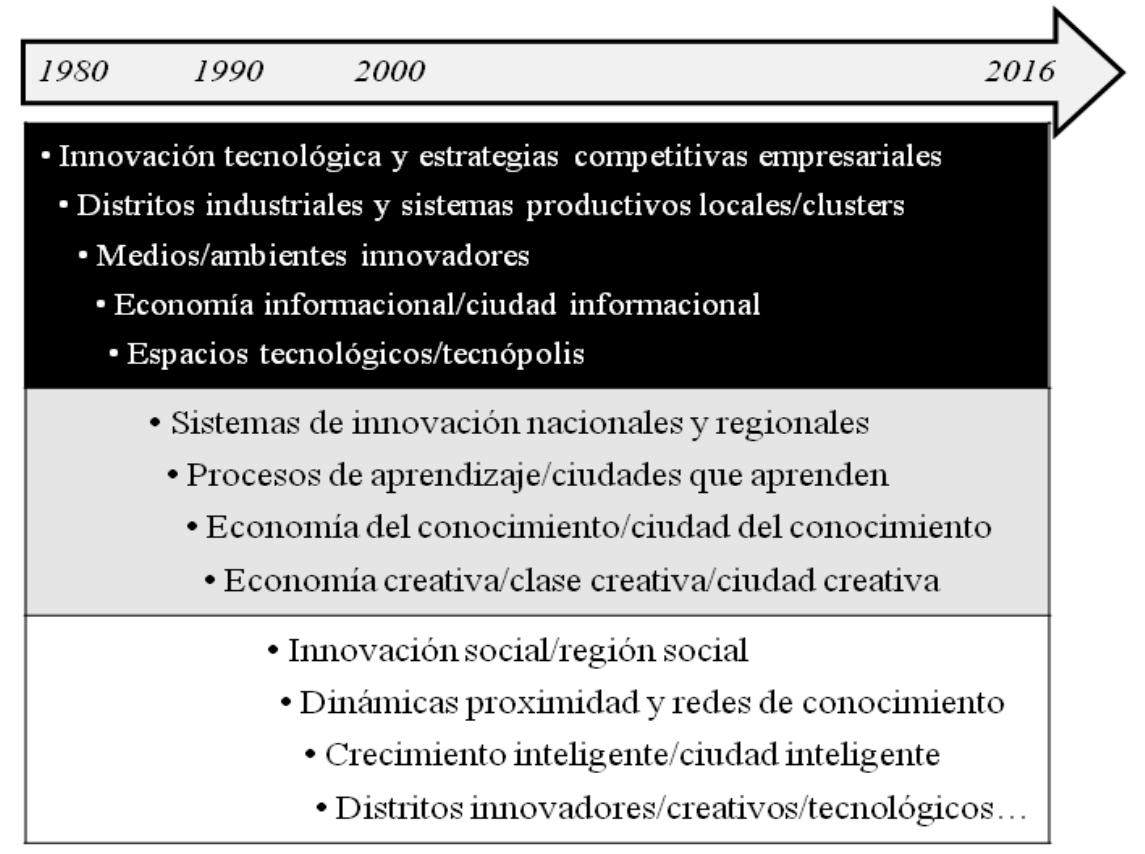

Fuente: Elaboración propia.

A partir del trabajo pionero de Freeman (1974), se recuperó el significado estratégico de la innovación tecnológica para mejorar la competitividad de las empresas en un contexto de crisis del fordismo como el que se experimentaba en esos años (DOSI et al., 1988), aunque sin abordar ninguna preocupación territorial de forma explícita. Casi en paralelo, pero con unos objetivos más próximos a los aquí propuestos, los primeros estudios sobre distritos industriales (BECATTINI, 1979), clusters (PORTER, 1991) y ambientes innovadores (AYDALOT, 1986; MAILLAT; QUÉVIT; SENN, 1993) - que Moulaert y Sekia (2003) bautizaron como modelos territoriales de innovación - plantearon ya la especial capacidad de ciertos entornos locales o regionales para mejorar su eficiencia colectiva mediante redes generadoras de externalidades positivas, incorporando factores explicativos de índole cultural, histórica e institucional junto a los estrictamente económicos. Ese enfoque supuso una diferencia significativa respecto a quienes, situando en el centro de su análisis la revolución de las tecnologías de información y comunicación, analizaron la geografía construida por una nueva economía informacional (HALL; PRESTON, 1990) y su reflejo en la ciudad informacional (CASTELLS, 1995), sin olvidar especial atención suscitada por las tecnópolis o los parques tecnológicos y científicos (CASTELLS; HALL, 1994), principal exponente de esa revolución tecnológica.

Si esa primera década de estudios supuso una verdadera eclosión de nuevos conceptos, ideas y temáticas de investigación, la siguiente puede considerarse como de maduración, consolidando esas líneas emergentes e incorporando otras aportaciones especialmente significativas. Por un lado, los estudios sobre sistemas de innovación (LUNDVALL, 1992; COOKE, 2001) destacaron la importancia de las interrelaciones y acuerdos entre empresas, instituciones ligadas al conocimiento (universidades, centros de $\mathrm{I}+\mathrm{D}$, centros tecnológicos...) y administraciones públicas para aumentar los recursos disponibles y generar efectos multiplicadores. Por otro, la creciente atención prestada a los procesos de aprendizaje como 
base de la innovación justificó una emergente literatura sobre learning economy y learning cities, así como sobre las comunidades de práctica en que alcanza su máxima intensidad (FLORIDA, 1995; WENGER; SNYDER, 2000), aunque fue aún mayor la atención prestada al conocimiento y la creatividad como recursos estratégicos.

Al mismo tiempo, la creciente necesidad de avanzar hacia unas economías urbanas y regionales más basadas en la producción y aplicación de diferentes formas de conocimiento para enfrentar los retos de la globalización centró la atención en el valor de las industrias y servicios más intensivos en su uso, junto al de aquellos recursos humanos altamente cualificados, considerados esenciales para la nueva competitividad territorial y para redefinir la posición jerárquica de las ciudades del conocimiento en el sistema urbano (WINDEN et al., 2006; SCOTT, 2009). La propuesta de incorporar entre estas actividades a las industrias culturales, dotadas de un elevado contenido simbólico, justificó la emergencia de nuevas líneas de investigación sobre la economía creativa (DCMS, 1998), la clase creativa (FLORIDA, 2002), o las ciudades creativas (LANDRY, 2000), aunque aquejados por cierta heterogeneidad en cuanto al significado de la creatividad.

La evolución de este tipo de estudios en la última década ha moderado el surgimiento de nuevos conceptos y teorías mientras aumentan los estudios destinados a aportar evidencias empíricas, profundizar algunos desarrollos teóricos o proponer una revisión crítica de otros. Entre esas novedades, tal vez la más relevante sea la definitiva inclusión de la innovación social en la agenda de investigación, planteando no sólo la importancia del contexto social como factor de impulso o freno para la innovación, sino también de la acción colectiva como motor de tales procesos, orientados no tanto a mejorar la competitividad de empresas y territorios como a atender necesidades sociales identificadas localmente mediante nuevas formas de respuesta (MOULAERT et al., 2005b; KLEIN; HARRISON, 2007). También pueden destacarse los estudios sobre dinámicas de proximidad, que han profundizado en sus diferentes formas y su influencia sobre la desigual geometría que presentan unas redes de conocimiento generalmente multiescalares (BOSCHMA, 2005).

Finalmente, no pueden dejar de mencionarse los estudios sobre el ahora calificado como crecimiento inteligente, que tiene su traducción en las llamadas ciudades inteligentes o smart cities, así como en las ciudades digitales, nuevas metáforas entre las muchas utilizadas en los estudios urbanos de los últimos tiempos, que recuperan el discurso de las tecnópolis para destacar la utilidad de las tecnologías digitales en la construcción de ciudades más eficientes, mejor gestionadas y ambientalmente más sostenibles (KOMNINOS, 2002), o el interés por espacios en el interior de las ciudades que actúan como polos de innovación, denominados distritos innovadores, creativos o tecnológicos según los casos (COOKE; LAZZERETTI, 2008).

En resumen, una trayectoria de tres décadas, con la diversificación temática y de enfoques teóricos que acaba de señalarse, ha generado un patrimonio de conocimientos del que pueden seleccionarse algunas ideas que resultan particularmente pertinentes para replantear el significado de la innovación en una estrategia de resiliencia urbana post-crisis que sea económicamente eficiente y, al tiempo, socialmente inclusiva. Tal selección contiene, sin duda, un elevado componente subjetivo, fruto de la propia investigación realizada en este ámbito y de la elaboración de una propuesta interpretativa frente a otras alternativas posibles, pero aquí se intentará incidir en aspectos que actualizan algunas propuestas anteriores (MÉNDEZ, 2002). 


\section{INNOVACIÓN PARA LAS ÁREAS URBANAS}

El discurso sobre la innovación se ha difundido en ámbitos disciplinares y territorios de características muy diversas, por lo que suele aceptarse que un mayor esfuerzo en ese sentido puede contribuir a un mejor desarrollo económico y territorial. No obstante, cuando se profundiza en el significado del concepto y en sus múltiples manifestaciones es cuando aparecen discrepancias, que se repiten al considerar las estrategias más adecuadas para su promoción.

Frente a otras opciones posibles, el concepto de ciudad innovadora que aquí se propone las identifica, en primer lugar, como aquellas donde se aplica una estrategia sistemática orientada a producir, difundir y aplicar un recurso estratégico como es el conocimiento en sus diversas formas (analítico, sintético o simbólico), acumulado tanto en su población y sus empresas, como en sus instituciones públicas y sus organizaciones sociales. El objetivo prioritario será ampliar ese stock para así favorecer una mejora de las capacidades disponibles para promover el desarrollo local, incentivando tanto su producción interna como su transferencia desde el exterior y su aplicación práctica mediante formas de gobernanza adecuadas a ese fin. Para ello resultará esencial impulsar procesos de aprendizaje, tanto individual a través del sistema educativo, como colectivo a través de un trabajo conjunto que favorezca la transmisión de conocimiento tácito y difícil de codificar, para lograr así un aumento de lo que puede calificarse como inteligencia compartida. La forma de organización más eficaz para promover la innovación será, pues, la construcción de redes locales formalizadas o de carácter informal entre actores con características, estrategias e intereses diferentes, comprometidos en objetivos comunes. Pero en un mundo donde se densifican todo tipo de flujos multiescalares, junto a las redes locales habrá de prestarse una creciente atención a las relaciones que los actores urbanos mantengan con el exterior, pues no se trata de pretender convertir a las ciudades en islas de innovación desconectadas de su entorno.

Finalmente, frente a una visión de la innovación limitada al ámbito empresarial, construir una ciudad innovadora exigirá cierta complementariedad entre la innovación económica y la innovación social. Además de promover una economía urbana donde buena parte de las empresas realice un esfuerzo para aumentar la eficiencia de sus procesos de trabajo, mejorar la calidad de sus productos o servicios, su gestión interna o su acceso a nuevos mercados, se tratará de construir también ambientes socialmente innovadores, comprometidos con la búsqueda de nuevas y mejores soluciones en terrenos como la inclusión social, la protección y puesta en valor del patrimonio, la gestión urbanística y ambiental, etc. La acción combinada de ambas formas de innovación debería traducirse en la recuperación de una senda de desarrollo frente al declive urbano mediante la puesta en marcha de estrategias de resiliencia. Puede incidirse ahora en cada uno de esos apartados para hacer más precisa la argumentación, comenzando con una revisión del concepto de innovación y su diferente uso en la bibliografía internacional, para luego abordar cuestiones relativas a los recursos necesarios para su impulso, el diverso significado de la proximidad en la construcción de redes, o el carácter colectivo de estos procesos, que convierten a la innovación en una construcción social. 


\section{DE LA PRODUCCIÓN A LA INCORPORACIÓN DE INNOVACIONES Y EL SIGNIFICADO DEL ENTORNO}

Buena parte de los estudios sobre innovación han centrado su atención en la capacidad de países, regiones o ciudades para insertarse en una sociedad del conocimiento mediante la producción de innovaciones tecnológicas, la presencia de industrias y servicios intensivos en su uso, el papel de la ciencia y la investigación como base del desarrollo tecnológico, o la presencia de recursos humanos con elevado nivel formativo. La posición relativa de cada territorio quedará reflejada en indicadores como la inversión realizada en I+D, las publicaciones científicas generadas en sus universidades y centros de investigación, el registro de patentes o modelos de utilidad, etc., lo que supone una visión restrictiva del concepto que prioriza, sobre todo, las consideradas como innovaciones radicales.

Aunque este tipo de investigaciones ocupa un lugar muy destacado en una bibliografía internacional donde en los últimos tiempos ganan importancia relativa los textos procedentes de la llamada nueva geografía económica de corte neoclásico y del management, los estudios sobre innovación también han diversificado y han ampliado esta visión para incorporar nuevas dimensiones. Se ha prestado así creciente atención a los fenómenos de difusión y transferencia del conocimiento, destacando la desigual capacidad de absorción mostrada por ciudades y regiones (ABREU et al., 2008), lo que provoca a menudo la paradoja de la innovación (OUGHTON et al., 2002), pues las menos desarrolladas tienen también peores condiciones para acceder a unos recursos vinculados a políticas de I+D+i que acaban beneficiando, sobre todo, a las empresas, instituciones y territorios mejor dotados para competir y rentabilizar esas ayudas.

En el marco de esta perspectiva sobre la innovación, destaca asimismo el creciente interés que para una parte de los investigadores ha cobrado lo que el National Endowment for Science, Technology and the Arts (NESTA) del Reino Unido denominó innovación oculta. Ignorada por buena parte de los estudios y estadísticas oficiales sobre esta materia -debido a las evidentes limitaciones que presentan las métricas y criterios utilizados para medir el esfuerzo innovador- puede estar presente en muchos sectores de servicios e industrias maduras, ampliamente mayoritarios en muchas de nuestras ciudades, así como en todo tipo de empresas y organizaciones. Estas innovaciones ocultas son muy dependientes del hinterland de ideas en que surgen, lo que exigirá contar con una densa red de relaciones para identificar el stock de conocimiento útil disponible, acceder a él, adecuarlo y reutilizarlo, evidenciando la importancia de una buena conexión con el entorno. Al mismo tiempo, esto explica la frecuente inexistencia de una correlación directa entre las actividades de investigación y la capacidad de innovación mostrada por las ciudades, pues "[...] se puede ser innovador de muchas formas diferentes" (NESTA, 2007, p. 18).

Apostar por una visión restrictiva o amplia de la innovación supone modificar de forma sustancial el mapa resultante. Es indudable que la producción de I+D, el desarrollo de tecnologías de vanguardia, o la localización de las actividades más intensivas en conocimiento exige abundantes recursos económicos, capital humano y servicios de apoyo altamente especializados, por lo que es habitual su concentración en un reducido número de empresas ubicadas en las grandes áreas urbanas y las regiones más prósperas. Por el contrario, las innovaciones incrementales y ocultas pueden surgir en ambientes mucho más diversos, por lo

DRd - Desenvolvimento Regional em debate (ISSNe 2237-9029) 
que se trata también de una innovación distribuida en el territorio (FELT et al., 2007), que se adecúa a la evolución específica seguida por cada ciudad o región para definir así diferentes trayectorias de innovación. Esta perspectiva también aconseja revisar la frecuente estandarización de unas políticas de innovación que a menudo pretenden imitar las seguidas por territorios ganadores, donde han tenido éxito, consideradas como buenas prácticas generalizables, frente a la posibilidad de apostar también por un mejor aprovechamiento de los recursos locales como base para una renovación y mejora de su base económica e institucional (MÉNDEZ, 2013).

\section{LA DESIGUAL CAPACIDAD INNOVADORA DE LAS CIUDADES: UNA JERARQUÍA DE RECURSOS ESPECÍFICOS}

Hace más de dos décadas que los estudios sobre ambientes innovadores destacaron la importancia del entorno territorial para explicar la concentración de la innovación en ciertos lugares frente a su ausencia o escasez en otros. La influencia ejercida por la teoría de la estructuración y el significado que otorga a unos agentes sociales que no se limitan a reproducir las propiedades estructurales del sistema sino que pueden matizarlas, adecuarlas y, finalmente, transformarlas de forma gradual, junto a unos enfoques relacionales que interpretan sus actuaciones como fruto de la interacción, justificaron incorporar esas ideas para interpretar las claves de esa innovación localizada (BATHELT; GLÜCKLER, 2003). Se concedió así especial protagonismo a la presencia de actores locales (individuos, empresas u organizaciones) con voluntad, capacidad y disposición a asumir riesgos para poner en marcha todo un conjunto de acciones innovadoras destinadas a mejorar la competitividad de las empresas, generar más y mejor empleo, o elevar la calidad de vida urbana.

Frente a quienes consideran al territorio como simple soporte físico de la innovación, “[...] el lugar es más que una localización, es un sistema [...]" y por ello "[...] existe un efecto de lugar que orienta la acción de los actores [...]" (FONTAN; KLEIN; TREMBLAY, 2004, p. 122). Esa conciencia obligó a considerar también el patrimonio de recursos locales específicos que suponen diferentes formas de capital urbano - heredado del pasado o generado en el presente -, que puede movilizarse para cimentar la innovación, cuya escasez en cambio la dificulta. Más allá de un simple inventario, puede proponerse cierta jerarquización que presupone la necesidad de ciertos recursos materiales como condición necesaria, pero no suficiente si escasean otros recursos de carácter inmaterial, lo que permite dibujar una pirámide de recursos para la innovación de desigual importancia en función de su complejidad y el tiempo necesario para su acumulación (Figura 2). 
Figura 2 - Jerarquía de recursos locales para la innovación.

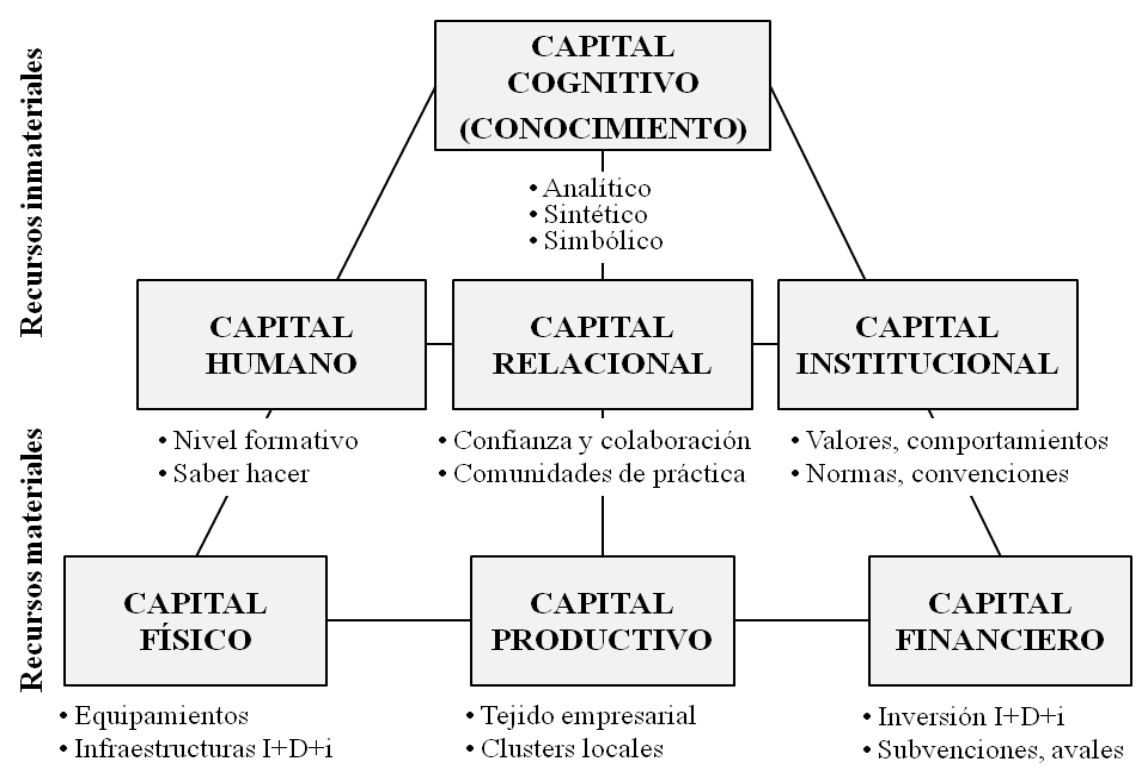

Fuente: Elaboración propia.

Se necesita, en primer lugar, cierta dotación de capital físico en forma de infraestructuras y equipamientos para la innovación, centros educativos de calidad, etc., junto a recursos financieros para realizar una inversión acorde con el reto planteado. Tanta o mayor importancia tiene el capital productivo, asociado tanto a las características de las empresas como a las del entorno empresarial y la existencia de interrelaciones que favorecen mayor eficiencia colectiva. Los modelos territoriales de innovación dieron así especial importancia a las externalidades tipo Marshall generadas en el interior de clusters territoriales de empresas especializadas en determinados productos o servicios. Pero aportaciones posteriores destacaron también las externalidades tipo Jacobs derivadas de la co-localización de actividades diversas y complementaras, patrimonio por lo general de las grandes áreas urbanas (VAN DER PANNE, 2004).

No obstante, buena parte de la literatura reciente sobre estos procesos ha concedido especial importancia a otro tipo de recursos intangibles como puede ser la presencia de trabajadores altamente cualificados, definidos habitualmente como capital humano aunque autores como Florida (2002) los identificaron con el talento o la clase creativa, así como de profesionales con un saber hacer fruto de la experiencia y la práctica, cualquiera que sea su nivel formativo. También la densidad de capital social, que constituye el adhesivo necesario para que surjan relaciones de confianza y puedan construirse comunidades de práctica entre quienes comparten claves y saberes comunes (AMIN; ROBERTS, 2008). Por último, ha despertado particular interés el capital institucional, entendido como un conjunto de valores, normas de comportamiento, reglas o convenciones - a veces materializadas en organizaciones formales -, que pueden favorecer la creación de una cultura local innovadora o, por el contrario, mantener inercias que la obstaculicen.

Pero sin duda es el capital intelectual o cognitivo - identificable con el conocimiento -, el recurso que ha atraído mayor atención en las investigaciones de la última década, como

DRd - Desenvolvimento Regional em debate (ISSNe 2237-9029) 
factor clave en la generación de ventajas competitivas. De esa extensa bibliografía, en este caso sólo interesa destacar la presencia de diversas formas de conocimiento, con implicaciones también diferentes sobre las economías locales (ASHEIM et al., 2011). En un extremo está el conocimiento analítico, de carácter científico, abstracto y universal, altamente codificado y transmisible a distancia, que es predominante en determinadas industrias high tech y servicios altamente especializados, asociado a grupos profesionales con alto nivel formativo y territorios metropolitanos que cuentan con un entorno adecuado para su producción, circulación y aplicación. Algo similar ocurre con el conocimiento sintético, que se relaciona con saberes más ligados a la ingeniería y la aplicación del conocimiento analítico, que sólo permite una codificación parcial y exige cierta transmisión directa que favorece su concentración en grandes centros productivos especializados. Pero no puede olvidarse el conocimiento simbólico, relacionado con el saber hacer y con la aportación de ciertos valores culturales y significados (como la calidad, la diferenciación, el diseño, la identidad, etc.) a los productos y servicios, lo que alcanza especial importancia en los sectores culturales/creativos pero también está presente en muchas otras actividades, exigiendo para su transmisión el reconocimiento entre emisores y receptores, por lo que se asocia a ambientes específicos. Conocer y comprender el tipo de conocimiento presente en una determinada economía urbana será entonces fundamental para evitar propuestas de dinamización que supongan saltos en el vacío al exigir tipos de saberes inexistentes o con muy escaso desarrollo en el ámbito local.

\section{LA INNOVACIÓN COMO APRENDIZAJE INTERACTIVO: LOS DIVERSOS SIGNIFICADOS DE LA PROXIMIDAD.}

Tal como han destacado los enfoques relacionales, el proceso de innovación no es lineal sino interactivo, pues exige la colaboración entre múltiples actores cuya experiencia compartida retroalimenta el proceso (FLØYSAND; JACOBSEN, 2010). De ahí su estrecha vinculación con la construcción de redes de intercambio de conocimiento, ya sea entre empresas, de estas con las instituciones generadoras o que transfieren ese conocimiento, con sus clientes o proveedores, con las administraciones públicas, las organizaciones sociales, etc., permitiendo un aprendizaje colectivo que es fruto de esa fertilización cruzada. En tal sentido, “[...] la interconexión y el papel de la colaboración, las redes, los clusters y los amplios impactos asociados con las externalidades derivadas son temas de importancia central en los estudios sobre innovación" (HOWELLS; BESSANT, 2012, p. 936). Por ello, tanto la densidad de los actores integrantes en la red, como el carácter vertical y jerárquico o, por el contrario, horizontal de las relaciones que mantienen entre ellos condicionará el tipo de resultados que cabe esperar del proceso innovador y su mayor o menor capacidad de difusión.

Los primeros estudios sobre el significado de estas redes constituidas por actores con características, intereses y estrategias de acción diversos, pero implicados en objetivo comunes y que mantienen relaciones de reciprocidad compartiendo recursos y riesgos, destacaron la importancia de la proximidad espacial entre ellos, prestando especial atención a las conexiones de ámbito local por considerar que esa cercanía facilitaba, mediante el contacto frecuente y a menudo informal, la transmisión de conocimiento tácito. En ese sentido, si redes amplias pueden animar la participación y favorecer una innovación más abierta, se valoraba que al mismo tiempo fuesen acotadas en el plano territorial para facilitar 
el surgimiento de relaciones de confianza capaces de generar mayor compromiso y estabilidad a la red.

La primacía de la escala local fue más tarde cuestionada por quienes consideran que, en un contexto de creciente globalización de los procesos, el local networking resulta insuficiente para comprender la desigual capacidad de los territorios respecto a la generación de innovaciones. Eso obligó a conceder creciente importancia a las relaciones que se establecen a larga distancia, cada vez más densas, pues en bastantes casos la innovación local depende de los flujos de conocimiento y de otros recursos procedentes del exterior, capaces de compensar a veces las debilidades internas, lo que convierte a la conectividad global del lugar en factor de impulso o freno según los casos (BATHELT et al., 2004; VALE, 2009). No obstante, frente a visiones dicotómicas, ambos tipos de relaciones pueden considerarse complementarias, lo que supone afirmar que la innovación tiene un carácter multiescalar.

Figura 3. Diversas formas de la proximidad para promover la innovación.

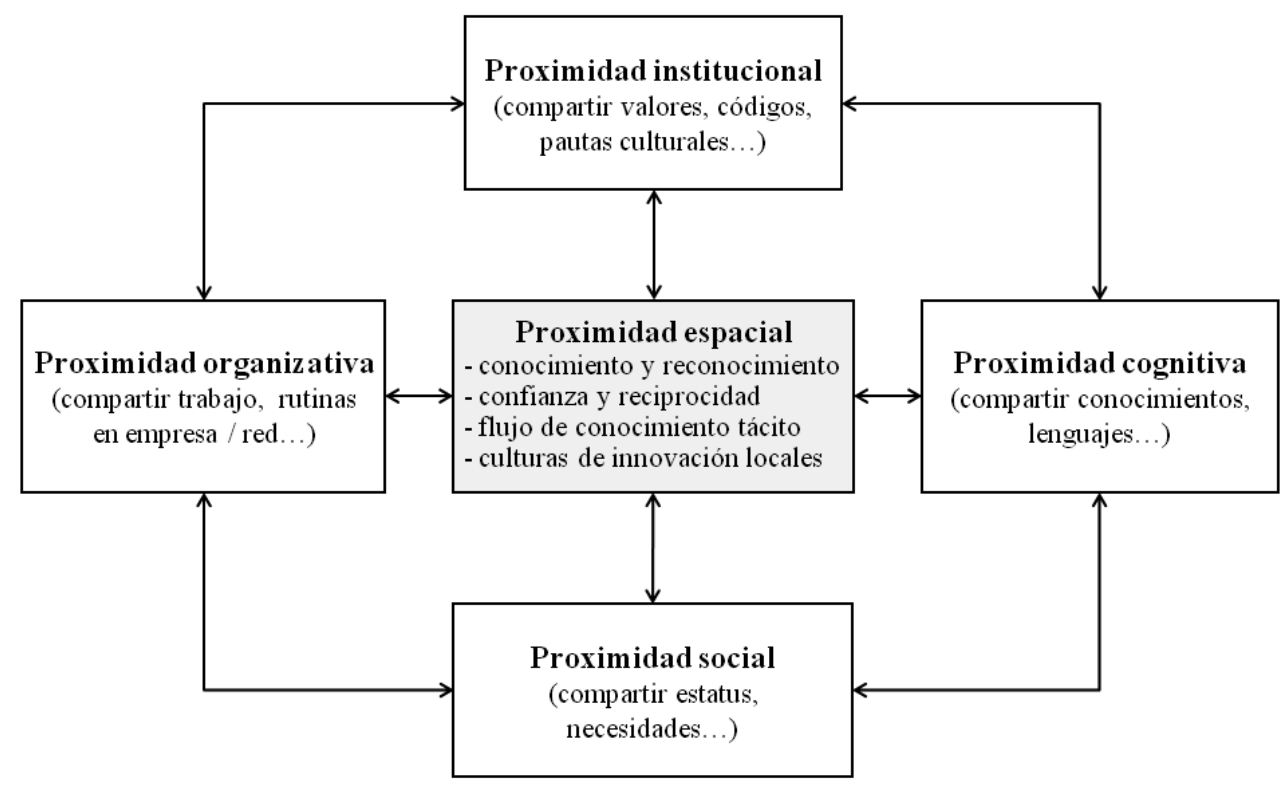

Fuente: Elaboración propia.

Pero ese debate obligó también a realizar una reflexión más profunda sobre el concepto de proximidad y las dinámicas derivadas, no influidas tan sólo por la simple distancia física (BOSCHMA, 2005). Sin duda esa cercanía geográfica se verá reforzada -en ocasiones sustituida - si se le suman otras complementarias: (i) proximidad institucional, entre actores que comparten valores, pautas culturales y códigos comunes; (ii) proximidad cognitiva, cuando comparten una base de conocimientos y un lenguaje específicos; (iii) proximidad organizativa, cuando lo que les une son pautas y rutinas de trabajo habituales en el seno de una misma organización; (iv) proximidad social, cuando se comparte estatus y la distancia social entre ellos es reducida. Al mismo tiempo, la propia pertenencia a una red de conocimiento y la experiencia de un aprendizaje y unas tareas compartidas tenderá a reforzar, en bastantes casos, los vínculos iniciales, lo que permite hablar de una proximidad construida que no es un dato preexistente a la innovación y evolucionará con la propia red (BALLAND; BOSCHMA; FRENKEN, 2015). Pero, tal como muestra la figura 3, aquí se reivindica la 
persistente importancia de una proximidad espacial vinculada a la co-localización entre los actores de la innovación que permite su conocimiento y reconocimiento mutuo, base para establecer relaciones de reciprocidad sustentadas en cierto grado de confianza mutua que facilitarán el intercambio de conocimiento tácito y no codificable.

\section{LA INNOVACIÓN COMO PROCESO COLECTIVO Y CONSTRUCCIÓN SOCIAL}

Hace ya dos décadas, el Libro Verde sobre la Innovación editado por la Comisión Europea afirmó que

[...] la innovación no es únicamente un mecanismo económico o un proceso técnico. Ante todo es un fenómeno social a través del cual los individuos y las sociedades expresan su creatividad, sus necesidades y sus deseos. De esta forma, independientemente de su finalidad, sus efectos o sus modalidades, la innovación está estrechamente imbricada en las condiciones sociales en que se produce (COMISIÓN EUROPEA, 1995, p. 17).

Frente a la frecuente primacía concedida a la innovación empresarial y a sus cuatro dimensiones (procesos, productos, organización y mercados), así como a los actores (empresas, gobiernos, instituciones relacionadas con el conocimiento) presentes de forma habitual en los modelos de triple hélice (ETZKOWITZ; LEYDESDORFF, 1997), esta perspectiva permitió ampliar tanto el significado de la propia innovación como el número de los potenciales actores capaces de generarla y difundirla.

La progresiva incorporación del concepto de innovación social, que se difundió desde comienzos de este siglo, resulta ahora indispensable para plantear el significado actual de la innovación (MOULAERT et al., 2005b), lo que conlleva reivindicar la práctica de una geografía socioeconómica que no disocie esos dos componentes de la realidad urbana.

En primer lugar, esta propuesta supone que la innovación debe entenderse como la capacidad para producir, incorporar, transferir y ofrecer respuestas nuevas que puedan aportar soluciones no convencionales a los problemas existentes en un determinado lugar, tanto en el plano de la efíciencia económica como en otros también vinculados al desarrollo territorial (como el bienestar social, la sostenibilidad ambiental o el buen gobierno), poniendo en juego capacidades y competencias diversos. Eso justifica que la demanda de innovación aumente cuando también se incrementan las necesidades sociales insatisfechas, algo habitual tras cada crisis cíclica del capitalismo. Tal como ya afirmaba el propio Libro Verde, eso puede incluir iniciativas que generen más empleo, promuevan nuevas formas de trabajo o aumenten su calidad, economicen recursos naturales y energéticos o limiten los residuos generados, favorezcan la inserción de colectivos en riesgo de exclusión, mejoren la oferta de servicios a la población, la eficacia y transparencia de la gestión pública, etc.

Pero al mismo tiempo, la innovación es una construcción social y territorial para la que el ambiente cultural y los actores sociales están presentes a lo largo de todo el proceso imprimiéndole ciertas características, por lo que puede afirmarse que existen culturas de innovación localizadas que se reflejarán en trayectorias locales específicas (KLEIN; ROY, 2013). A su vez, aunque es innegable el protagonismo que a veces adquieren determinados

DRd - Desenvolvimento Regional em debate (ISSNe 2237-9029) 
individuos, gobiernos u otras organizaciones, cualquier práctica socialmente innovadora es resultado de una acción colectiva que activa redes sociales de innovación - preexistentes o creadas al efecto - basadas en la colaboración y con una finalidad común, por lo que una mayor densidad asociativa puede ser un factor potencial de innovación en determinados espacios urbanos.

Se ha afirmado recientemente que "[...] la ciudad es un ámbito esencial a la hora de intervenir y experimentar en momentos en que están en marcha grandes cambios y en los que las respuestas convencionales no parecen funcionar" (SUBIRATS, 2015, p. 7). En consecuencia, la innovación económica y la innovación social no deben entenderse como antagónicas sino como complementarias, tanto para renovar y hacer más competitivas economías urbanas dañadas por el impacto de la crisis financiero-inmobiliaria, la consiguiente recesión económica y el efecto añadido de las políticas de austeridad fiscal, como para regenerar su tejido sociolaboral, mejorar la calidad y cohesión de su espacio interno, o establecer y poner en práctica nuevas regulaciones que promuevan una urbanización más sostenible. Se tratará, pues, de construir redes de valor que "[...] reúnan a los más diversos actores del territorio para aportar una respuesta concreta gracias al ensamblaje de fragmentos de innovación" (DESFORGES et al., 2013, p. 17).

Recordar ideas como las que acaban de sintetizarse, herederas de un pasado reciente de trabajo colectivo, puede resultar por ello de utilidad para enfrentar los retos del presente y del futuro inmediato con cierta perspectiva, identificar posibles alternativas para las economías urbanas y fijar la atención en algunas actividades y prácticas insuficientemente atendidas hasta ahora. Este será el contenido a desarrollar en los próximos epígrafes

\section{INNOVACIÓN PARA ECONOMÍAS URBANAS EN TRANSICIÓN: PROPUESTAS EN EL CASO ESPAÑOL.}

Las ciudades españolas se encuentran en transición entre un pasado reciente donde a una fase de intenso crecimiento y generación de empleo sucedió otra de crisis profunda, frente a un futuro incierto para el que a menudo no llegan a plantearse propuestas consistentes destinadas a revitalizar y, al tiempo, renovar sus economías. Conviene ahora recordar que durante más de una década se apostó por un crecimiento sin innovación, basado en un masivo recurso al crédito y el consiguiente endeudamiento de familias y empresas, que alimentó sobre todo la expansión de actividades de baja productividad y muy sensibles al ciclo económico como la construcción, las industrias auxiliares o los servicios al consumo, junto al sector financiero y de seguros, frente al retroceso generalizado de la industria y la moderada expansión de los servicios intensivos en conocimiento. Un limitado esfuerzo inversor en $\mathrm{I}+\mathrm{D}+\mathrm{i}$, junto a una baja proporción de ocupaciones altamente cualificadas dentro de la población activa, en contraste con el rápido aumento del empleo con bajas exigencias formativas y precario, consolidaron unas economías urbanas muy vulnerables, sobre todo en aquellos territorios donde las burbujas crediticia e inmobiliaria alcanzaron mayor dimensión.

La crisis de esta economía financiarizada y de escasa competitividad exterior ha transformado la geografía económica española (ALBERTOS; SÁNCHEZ HERNÁNDEZ, 2014), afectando con especial intensidad a sus áreas urbanas. La gravedad del impacto fue

DRd - Desenvolvimento Regional em debate (ISSNe 2237-9029) 
mayor en aquellas más vulnerables por su exposición al riesgo y la elevada presencia de empresas y grupos sociolaborales más frágiles (MÉNDEZ; ABAD; ECHAVES, 2015). Resultó, en cambio, algo menor en aquellas otras que a su diversificación económica sumaron un destacado esfuerzo por renovar su base productiva, crearon así empleos de calidad y más estables, o contaron con mayor presencia de actividades generadoras de elevado valor añadido. En cualquier caso, el reto de reorientar su economía puede considerarse común a todas las ciudades y, en esa perspectiva, la innovación y el conocimiento vuelven a ocupar un lugar destacado en la mayoría de propuestas realizadas en estos años.

La única excepción la constituyen aquellas de carácter continuista que confían en lograr la recuperación a partir de un contexto internacional expansivo que genere elevada liquidez, permita recuperar el crédito a niveles similares a los de antes de la crisis y reactivar el sector inmobiliario, además de mantener el dinamismo del sector turístico, dos pilares esenciales del crecimiento anterior. Para ello, el mercado debería seguir siendo el mecanismo regulador que seleccione las actividades de futuro mientras los diferentes gobiernos del Estado multinivel deberían centrar su tarea en mantener unas cuentas públicas saneadas, aprobar nuevas reformas que flexibilicen aún más todo tipo de mercados, facilitar la inversión empresarial y recuperar un planeamiento expansivo.

Frente a estas han surgido otras que, pese a su diversidad, tienen en común la necesidad de impulsar un profundo cambio estructural que reoriente el modelo productivo y de desarrollo urbano, recuperando también la función promotora y reguladora del sector público (FUNDACIÓN IDEAS, 2010; FEDEA, 2010; FUNDACIÓN $1^{\circ}$ DE MAYO Y FUNDACIÓN LARGO CABALLERO, 2011; DÍAZ DE SARRALDE; ESTRADA, 2015). Con diferente énfasis en las medidas que se proponen, todas plantean alternativas que permitan avanzar hacia un crecimiento inteligente (economía más basada en el conocimiento y la innovación), sostenible (economía más ecológica y que utilice los recursos de manera eficiente) e integrador (economía con elevados niveles de empleo, que genere cohesión social y territorial), acorde con los objetivos de la Comisión Europea (2010). Aunque las propuestas originarias no consideran de forma explícita a las ciudades, sus planteamientos pueden trasladarse a esta escala y definen tres líneas de actuación para las que la innovación tiene una importante función a cumplir.

En primer lugar, el concepto de especialización inteligente que la retórica oficial de la Comisión Europea ha puesto de actualidad plantea la necesidad de una transformación estructural que impulse acciones orientadas en tres direcciones principales. Por un lado, una transición que favorezca el desarrollo de actividades intensivas en conocimiento para así modernizar su estructura sectorial, lo que supone insistir en la importancia de las industrias high tech y los servicios avanzados a las empresas, junto al sector cultural y las industrias creativas. Por otro lado, una modernización que fomente el esfuerzo innovador en actividades tradicionales para mejorar su competitividad, identificando aquellos sectores acordes con las capacidades y trayectorias de cada lugar. Finalmente, una diversificación que favorezca la consolidación de clusters innovadores locales y regionales constituidos por empresas interrelacionadas de sectores diversos, que desarrollen sinergias y procesos de aprendizaje colectivo entre ellas (SÁNCHEZ MORAL, 2015, p. 53). Lo destacable en este argumento es la reorientación de las políticas de promoción para apoyar una especial acumulación de factores de localización inmateriales que son clave para la innovación (trabajadores cualificados, cultura empresarial, marco institucional propicio a la innovación, calidad de vida urbana...), sin ignorar los de carácter más tradicional y tangible. 
En segundo lugar, a la conveniencia de actividades y empleos más cualificados y de mayor calidad hoy se suma la necesidad de impulsar un uso más sostenible de los recursos naturales y una menor disociación entre los sistemas económico y ecológico. Se apuesta así por avanzar hacia una economía calificada como circular, reduciendo su elevada huella ecológica mediante el apoyo a dos tipos de acciones complementarias. Por un lado, la promoción de una cultura ambiental y del territorio respetuosa con el uso de los recursos renovables y no renovables que apoye la transición energética, incorpore indicadores no solo monetarios para valorar las actividades económicas y favorezca un consumo responsable. Al mismo tiempo, la apuesta por una economía verde,

[...] de baja intensidad en carbono, en materia y en energía, que utiliza los recursos de forma eficiente, que es socialmente incluyente y que además ofrece, en el marco de la sostenibilidad, nuevas oportunidades no sólo ambientales, sino socioeconómicas y tecnológicas en términos de competitividad, empleo sostenible y estabilidad a largo plazo (JIMÉNEZ HERRERO, 2012).

Las estrategias para favorecer una reorientación de las economías urbanas en esta dirección pasarían por el apoyo directo a actividades emergentes con impacto positivo sobre el medio ambiente (energías renovables, gestión y reciclaje de residuos, tratamiento y depuración de agua, regeneración de paisajes, etc.). Pero también se puede fomentar el empleo verde renovando sectores tradicionales para así reducir los insumos necesarios o sus efectos contaminantes (rehabilitación de inmuebles para mejorar su eficiencia energética, fabricación de vehículos eléctricos e híbridos, turismo sostenible, promoción de circuitos cortos de alimentación, etc.).

En tercer lugar, a lo anterior se añade la creciente atención prestada a la ahora denominada economía de cuidados (PAZOS; MEDIALDEA, 2015). En el ámbito europeo hace ya dos décadas que se señaló la creciente demanda por la población de una serie de servicios de proximidad que debían convertirse en un yacimiento de empleo con una importancia cada vez mayor: asistencia a personas mayores y dependientes (ayuda domiciliaria, centros de día, teleasistencia, residencias...), apoyo a jóvenes e inmigrantes con dificultades de inserción, guardería de niños en edad preescolar, protección y restauración ambiental, etc.

Muchas ciudades se enfrentan hoy a la necesidad de ampliar y reordenar ese sistema, tanto para mejorar las condiciones de vida de colectivos especialmente vulnerables, como por la insuficiente capacidad pública y del Tercer Sector no lucrativo para atender esa demanda en expansión. También por su posible aportación a la recuperación económica, al ampliar la oferta de empleos directos e indirectos en actividades que suelen tener una localización dispersa, relacionada con la de sus usuarios potenciales, pudiendo así ayudar a la dinamización de determinadas áreas urbanas y barrios con especiales carencias. El deterioro del Estado de Bienestar provocado por las políticas neoliberales de austeridad como respuesta a la crisis ha obligado a considerar el necesario protagonismo que las organizaciones ciudadanas y las empresas integradas en la economía social deben tener en el desarrollo de estas actividades.

En definitiva, cualquiera de estas tres propuestas destinadas a promover una reestructuración de las economías urbanas dentro de una estrategia global de resiliencia y adecuada, en cada caso, a sus específicas capacidades y limitaciones constituye una vía que merece ser explorada. Pero aquí se va a centrar la atención en el significado que para esa 
recuperación pueden tener un conjunto de iniciativas, prácticas y entidades que suelen calificarse como alternativas, destacando su carácter emergente en el momento actual, definiendo sus perfiles y precisando su carácter innovador desde diferentes perspectivas.

\section{ECONOMÍA ALTERNATIVA PARA REORIENTAR EL DESARROLLO URBANO.}

La revisión crítica de modelos de crecimiento que han demostrado su ineficacia, inequidad e insostenibilidad, así como la necesidad de atender de forma urgente los negativos impactos provocados en las sociedades y los espacios urbanos por una crisis sistémica como la padecida, hace aumentar ahora el interés por un conjunto heterogéneo y bastante atomizado que puede integrarse bajo la denominación genérica de economía alternativa (MÉNDEZ, 2015). Pueden recordarse algunas de sus características, establecer una tipología de actividades a incluir, justificar las claves de su expansión reciente y señalar sus vínculos potenciales con procesos de innovación que pueden contribuir a la resiliencia urbana.

El de concepto de alternativo resulta, en principio, algo impreciso, calificado como “altamente inestable y relacional" (LEYSHON; LEE; WILLIAMS, 2003, p. 17), que puede incluir tanto prácticas que plantean una sustitución de la lógica capitalista, como otras que proponen complementarla en segmentos no bien cubiertos por el mercado o el Estado, con frecuentes situaciones de hibridación. Según Etxezarreta (2014, p. 11), “[...] puede transmitir la idea de una manera diferente de hacer las cosas - consumo alternativo, banca alternativa, fiscalidad alternativa -, o también puede significar algo totalmente diferente de lo que ya existía" y, en ese sentido, "[...] no es lo mismo una propuesta, un medio, un instrumento alternativo para resolver un problema específico, que una sociedad alternativa que tiene por objeto subvertir la existente". Algo más compleja y pormenorizada es la definición de Lorthiois (2002), quien propone entender el término alternativo aplicado a la economía:

(i) como otra forma de hacer, que transforma los modos de acción habituales para darles un sentido y una utilidad nuevos, reutilizando las herramientas de la economía convencional para incluir a segmentos sociales habitualmente excluidos (del mercado laboral, el consumo, la financiación, etc.);

(ii) como ir más allá del marco establecido para explorar nuevas formas de actividad, con nuevos actores que establecen relaciones de reciprocidad para acceder a bienes y servicios antes no accesibles, tal como ocurre, por ejemplo, con las monedas sociales, los bancos de tiempo, etc.;

(iii) como alteridad, en tanto promueve la diversidad y la diferenciación de productos o servicios, convertidas aquí en criterio de calidad, lo mismo que el mestizaje que genera una economía más plural, valorando también aquellas iniciativas que aproximan lo que está distante (productores y consumidores, ciudad y campo, excluidos e incluidos, etc).

El concepto de economía alternativa resulta, por tanto, próximo a los de economía social y economía solidaria, pero también mantiene diferencias significativas con ambos. Respecto a la primera, no considera el estatus jurídico (cooperativa, mutualidad, asociación, 
fundación) como una garantía suficiente ni de su democracia interna, ni de una lógica competitiva distinta a la convencional, ni de una aportación al bienestar social que beneficie necesariamente a quienes no pertenecen a esa empresa u organización. Respecto a la segunda, esta se define por sus valores y su finalidad, pero no todas las prácticas solidarias proponen una alternativa a la economía dominante ni conllevan un proyecto verdaderamente transformador. Por el contrario, la economía alternativa plantea un enfoque crítico que invita a repensar las reglas del juego, aunque su materialización sea muy diversa y sólo una investigación directa permitirá comprobar en qué medida experiencias concretas que se acogen bajo este calificativo lo son en la práctica. Por su parte, el concepto de economía colaborativa (sharing economy), también próximo, suele aludir de forma mayoritaria a iniciativas que utilizan plataformas digitales para poner en contacto a diferentes productores, consumidores, o a unos con otros, pero en bastantes casos sus objetivos no tienen una finalidad de mejora social ni pretenden una acción transformadora (BAUWENS, 2012).

Otro rasgo a destacar, coherente con el anterior, es la defensa de una economía con valores como los de "[...] equidad, transparencia, democracia, solidaridad, participación, sostenibilidad ambiental, inclusión social, etc." (ASKUNZE, 2013, p. 114). En un momento como el actual, la dimensión alcanzada por la desigualdad y los procesos de exclusión exige revisar de forma crítica la lógica económica imperante para promover una economía que esté al servicio de la sociedad. Cobra así creciente sentido una solidaridad que busque una mayor integración entre lo económico y lo social, pero no una solidaridad débil de tintes filantrópicos y paternalistas, destinada a combatir la pobreza, sino una solidaridad fuerte, destinada a ampliar la democracia real, la emancipación y frenar la desigualdad mediante formas de autoorganización colectiva (LAVILLE, 2016). Eso supondrá defender una economía diferente en un contexto plural y diverso (GIBSON-GRAHAM, 2008), donde la justicia social y espacial primen sobre la maximización de la plusvalía, la cooperación sobre la competencia, el trabajo sobre el capital, o la responsabilidad compartida sobre la concentración del poder. La traducción de esta racionalidad ajena a la socialmente dominante en prácticas concretas estará sometida, sin duda, a múltiples dificultades, por lo que su presencia efectiva variará en intensidad y forma según contextos espacio-temporales concretos.

Materializar una economía alternativa basada en principios solidarios exige construir redes de colaboración entre actores diversos, por lo general de escasa entidad en las economías urbanas, que incluyen tanto a individuos que participan como productores autónomos o usuarios/consumidores, micro y pequeñas empresas, entidades de la economía social, etc. Si su reducida dimensión es un rasgo habitual, respecto a sus objetivos y su grado de implicación parece frecuente la coexistencia de los que Conill et al. (2012) definieron como actores culturalmente transformadores - implicados en la construcción de otra economía para una sociedad diferente - con practicantes alternativos - incorporados de forma circunstancial en relación con el impacto provocado por la crisis, frente a unos actores mayoritarios y culturalmente adaptados que se mantienen ajenos a estas prácticas. Sin duda cobra especial protagonismo el primero de esos grupos, cuyos integrantes consideran que tanto en su trabajo como en su consumo están implícitos objetivos políticos orientados hacia una transformación ética de la sociedad a partir de cambios que se introducen en la vida cotidiana, con una destacada presencia de "[...] colectivos de las vanguardias sociales, muchos de ellos cualificados y al tiempo en riesgo de exclusión social, como ocurre con la mayoría de jóvenes que se implican en estos movimientos" (LLOBERA, 2013). Las relaciones que se tejen entre esos actores son a menudo informales, sin vínculos contractuales

DRd - Desenvolvimento Regional em debate (ISSNe 2237-9029) 
o limitados a acuerdos concretos, de carácter horizontal y no jerárquico, lo que resulta más fácil en redes de pequeño tamaño y con un ámbito espacial limitado, aunque la transescalaridad no está ausente en relaciones que se tejen en un contexto de creciente globalización, con las redes digitales como vehículo para canalizar esos flujos. Pero destaca especialmente la importancia del lugar, pues a menudo este tipo de red alternativa " [...] surge desde el territorio, de sus gentes y sus organizaciones, está enraizada en el territorio, utiliza los recursos endógenos y fomenta las capacidades locales para la creación de un entorno innovador" (GURIDI; PÉREZ DE MENDIGUREN, 2014, p. 56).

Figura 4 - Tipos de entidades y prácticas económicas alternativas en áreas urbanas.

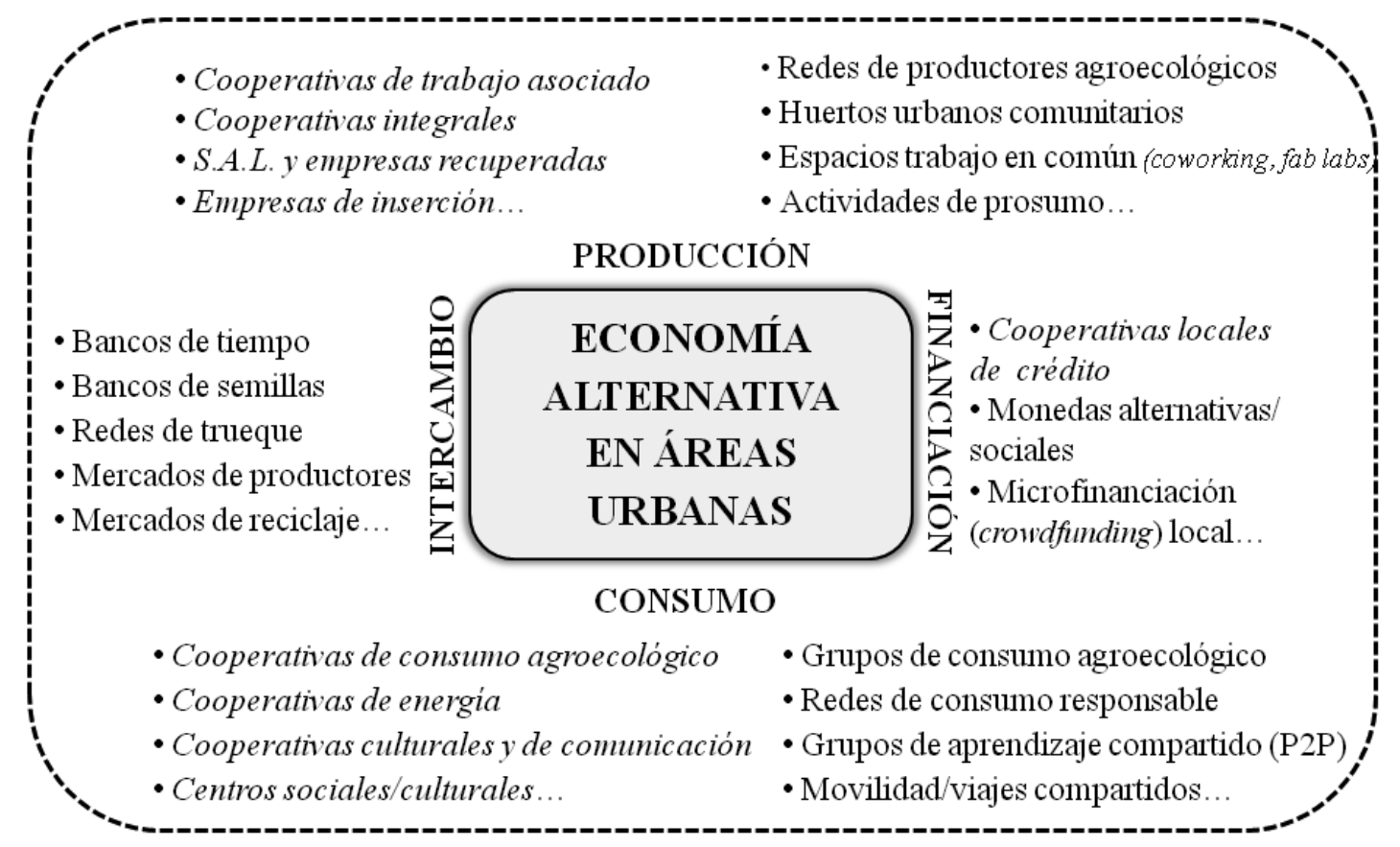

Fuente: Elaboración propia, a partir de Méndez (2015).

A partir de esos criterios puede proponerse una tipología de entidades y de prácticas a incluir dentro de estas formas de economía presentes en áreas urbanas y periurbanas, si bien en todas ellas existirá una gradación en cuanto al carácter más o menos alternativo de su práctica cotidiana. Si se organizan por su función predominante dentro del circuito económico, pueden identificarse cuatro tipos básicos (figura 4). Están, en primer lugar, las vinculadas con la producción de bienes o servicios, que pueden incluir diversos tipos de cooperativas, sociedades laborales y empresas de inserción, junto a redes de pequeños productores, huertos comunitarios urbanos, espacios de trabajo en común o coworking, etc. Un segundo grupo se relaciona con el intercambio, incluyendo desde redes de trueque a bancos de tiempo, de tierras y semillas, mercados de productores de proximidad o mercados de reciclaje. Un tercer grupo corresponde a diversas formas de consumo colaborativo, desde grupos y cooperativas de consumo agroecológico, algunas redes de movilidad y de educación compartida, centros sociales y culturales, etc. Un último grupo incluye aquellas finanzas 
alternativas con anclaje territorial como las monedas sociales, las cooperativas locales de crédito o la microfinanciación (crowdfunding) de proximidad.

Aunque no puede medirse con precisión la importancia relativa y evolución de estas actividades, parece indudable su expansión en tiempos recientes, primero como reflejo de los efectos provocados por la globalización neoliberal y los fenómenos de exclusión derivados, pero luego como resultado de la crisis de ese modelo, sumando así dos tipos de factores que convergen en las áreas urbanas sin que sea fácil delimitar su influencia respectiva. Por una parte, se ha ampliado la base social de malestar y descontento con el sistema, al menos entre ciertos colectivos movilizados que cuestionan tanto la lógica productivista, el hiperconsumismo o la mercantilización del espacio. Al mismo tiempo, otros se incorporan ante la imposibilidad de mantener su empleo o sus niveles de consumo anteriores en el contexto de precarización laboral y empobrecimiento de las clases medias que conlleva la salida de la crisis que la racionalidad neoliberal impone. La voluntad de unos por promover otros modos de vida, junto a la necesidad de otros expulsados de una economía progresivamente excluyente no sólo explica su crecimiento, sino que también cuestionan a quienes siguen considerando estas prácticas como anecdóticas y con escaso recorrido futuro. A todo ello debe añadirse que la economía alternativa puede considerarse también una fuente de innovaciones y concretar esa afirmación exige dedicarle un último apartado del texto.

\section{LA ECONOMÍA ALTERNATIVA COMO LABORATORIO DE INNOVACIÓN SOCIAL}

Tal como ya se ha señalado, en periodos de crisis como el padecido por nuestras ciudades la innovación resurge como respuesta estratégica para enfrentar los múltiples retos que se plantean, tanto en el plano económico como social o ambiental, y las consiguientes incertidumbres sobre su futuro inmediato. No obstante, esa alusión ya tópica al valor de la innovación puede tener luego una traducción muy diversa en cuanto a propuestas de acción, resultado de los distintos significados que hoy presenta este concepto.

La visión que puede considerarse hoy dominante, tanto en la investigación académica como en el discurso y la práctica política, es la que vincula innovación con ciencia, tecnología, conocimiento, talento, actividades intensivas en su uso o espacios que concentran esos recursos. Esta identificación conlleva una visión selectiva y bastante excluyente de los actores con capacidad para innovar, que son los integrantes habituales de los sistemas de innovación (empresas, centros de producción o transferencia de $\mathrm{I}+\mathrm{D}+\mathrm{i}$, instituciones públicas), de los clusters considerados como innovadores (industrias de alta intensidad tecnológica, servicios avanzados a empresas, finanzas y seguros, educación e investigación, industrias y servicios creativos...), o de las áreas urbanas relevantes en el mapa de la innovación (grandes ciudades, aglomeraciones metropolitanas, tecnopolos...), frente a una escasa atención hacia el resto.

Con el paso del tiempo también se ha renovado el propio significado de la innovación para hacerlo más amplio e inclusivo. La creciente atención prestada al concepto de innovación social ha contribuido a esa perspectiva renovada que no debe ser ignorada en los estudios urbanos actuales. Conceptos como los ya mencionado de innovación oculta e innovación 
distribuida han venido a destacar la presencia - al menos potencial - de procesos de innovación en numerosas actividades, empresas y organizaciones, la multiplicación de actores sociales que pueden contribuir a su producción, difusión y aplicación, así como, la construcción de redes de innovación de pequeña escala asociadas a iniciativas económicas con objetivos más amplios que la exclusiva competitividad económica. Eso "[...] sugiere una perspectiva alternativa para aproximarse a la innovación desde un enfoque de economía moral" (PSARIKIDOU, 2015, p. 67) y permite afirmar que las prácticas económicas alternativas pueden ser un laboratorio de innovaciones sociales desde varios puntos de vista complementarios, que aquí se proponen para un debate aún necesitado de mucha más investigación empírica que valide, matice o cuestione algunas de estas afirmaciones.

En primer lugar, esas prácticas son innovadoras por la finalidad que plantean, buscando transformar el funcionamiento de la economía y la sociedad urbanas para dar respuesta a necesidades, ya sean de origen lejano o derivadas de la reciente crisis y las políticas neoliberales de austeridad, que se entienden como retos movilizadores. La economía alternativa supone, por definición, la búsqueda de ámbitos de experimentación y creatividad que proponen soluciones nuevas y diferentes a las convencionales con objeto de lograr una adaptación al contexto y una transformación necesaria para avanzar en una resiliencia urbana más inclusiva, lo que no sólo exigirá una recuperación y mejora de los indicadores económicos y sociales, sino también cierta capacidad de reinventar la ciudad para adecuarse al nuevo tiempo. De forma complementaria, a menudo busca también empoderar o emancipar a grupos sociales con capacidad de actuación tradicionalmente limitada y mejorar sus niveles de bienestar, lo que supone contestar una lógica economicista ajena a otro tipo de valores más allá de la estricta rentabilidad económica a corto plazo.

En segundo lugar, pueden ser innovadoras por la generación de nuevos productos o servicios adecuados a la satisfacción de esas necesidades y aspiraciones no cubiertas adecuadamente por el mercado y el Estado, o que buscan reducir la huella ecológica de la actividad económica y ampliar el ciclo de vida de los bienes existentes. Las monedas sociales, los bancos de tiempo, el micro mecenazgo, los huertos comunitarios, los mercados de reciclaje o determinadas formas de movilidad y educación compartida son, entre otros, algunos de sus ejemplos más conocidos y su progresiva difusión es prueba de su utilidad, al margen de modas pasajeras. Tal como señala Lévesque (2011), su uso puede cobrar sentido bien con una finalidad reparadora, que busca paliar las externalidades negativas del sistema o de su crisis, bien con una finalidad transformadora, que promueve otro modelo de desarrollo urbano.

En tercer lugar, constituyen una innovación social por promover procesos de organización donde prima el trabajo en común de diferentes actores para la co-construcción tanto de la oferta como de la demanda, a partir de vínculos colaborativos de carácter esencialmente horizontal, lo que también contribuye a cambiar las relaciones sociales a partir de la acción colectiva. Son, pues, innovadoras tanto por sus fines y los bienes o servicios ideados para satisfacerlos, como por los medios que utilizan. Esto supone que la aparición de este tipo de iniciativas y prácticas " [...] no sucede por un mero impulso individual/voluntario de un o una emprendedora social, sino que se gesta en procesos sociales de mayor alcance..., a través de los cuales surgen iniciativas de experimentación e innovación" (ETXEZARRETA et al., 2015, p. 20). 
Por último, en algunos casos la economía alternativa da origen a nuevas formas de gobernanza y colaboración con las instituciones públicas para generar un entorno más favorable a unas prácticas que con frecuencia enfrentan debilidades significativas y amenazas del entorno. La modificación de normativas y ordenanzas, un tratamiento fiscal específico dado por las haciendas locales, la formación en materia de gestión, o la difusión de estas actividades entre la población son algunos de los ámbitos más habituales de colaboración. Mayor ambición supone la incipiente política de promoción de clusters o parques de innovación social que han comenzado a suscitar creciente atención en la Unión Europea, definidos como concentraciones locales de actores vinculados a la economía alternativa y solidaria que "[...] constituyen un verdadero sistema cooperativo propicio para la innovación y la resolución de problemas sociales" (PERARD, 2015, p. 3).

\section{ALGUNAS REFLEXIONES FINALES.}

En su libro sobre el triunfo de las ciudades, Edward Glaeser comenzaba su argumentación recordando que las áreas urbanas "[...] han sido motores de innovación desde los tiempos en que Platón y Sócrates discutían en los mercados atenienses [...]" y ahí radica el principal secreto de su éxito, tal como ya afirmó Jane Jacobs hace medio siglo. A continuación hacía una importante matización en el sentido de que "[...] puede que la ciudad gane, pero muy a menudo sus ciudadanos pierden" (GLAESER, 2011, p. 13-14). Si algo cabe aprender de una crisis como la padecida, es que las ciudades no deberían volver a apostar por promover un crecimiento económico basado en elevados beneficios a corto plazo pero a costa de incrementar los riesgos derivados del endeudamiento masivo, el predominio de actividades de baja productividad, el empleo barato y poco cualificado, la creciente polarización social y desigualdad espacial, así como una elevada huella ecológica.

Tal como aquí se ha intentado plantear, una estrategia de revitalización económica y regeneración del tejido social de las ciudades exigirá potenciar una mejora de su competitividad, derivada de un mayor esfuerzo innovador en todo tipo de actividades, junto a una mayor presencia de aquellas intensivas en conocimiento y generadoras de mayor productividad, menor deterioro paisajístico/ambiental, empleos de mayor calidad y salarios más altos. Pero también afirmar que una innovación orientada tan sólo a mejorar la competitividad económica es insuficiente si se pretende un desarrollo urbano más inclusivo, equilibrado y sostenible, que reduzca el elevado grado de vulnerabilidad heredado.

Promover, pues, los estudios y las acciones públicas o privadas a favor de la innovación y de un aumento del stock de conocimiento es, sin duda, un buen punto de partida. Pero del mismo modo que en estas tres últimas décadas el concepto de innovación se ha ampliado y diversificado, prestando creciente atención no sólo a cómo producirla, sino también a cómo y dónde incorporarla y aplicarla para responder a necesidades concretas, resulta imprescindible apoyar acciones que pongan en marcha innovaciones tanto económicas como sociales para lograr que sus beneficios potenciales se difundan entre un mayor número de actividades y empresas, ciudadanos y espacios urbanos. Reconocer que no existe una única vía para promover la innovación, sino que caben estrategias diversas y complementarias, adaptadas a la específica trayectoria, dotación de recursos y capacidades de cada espacio

DRd - Desenvolvimento Regional em debate (ISSNe 2237-9029) 
urbano, será un complemento necesario para avanzar en esa dirección. Desde esta perspectiva abierta de la innovación, cobra sentido incorporar una reflexión teórica y mayor investigación empírica sobre esa otra economía que, bajo denominaciones diversas y no estrictamente coincidentes, parece cobrar creciente importancia en bastantes ciudades, pese a que la atomización de sus iniciativas y la ausencia de estadísticas al respecto dificulten su valoración.

Dice Marcelo Corti (2012, p. 27) que "[...] las ciudades son el lugar donde el cambio se imagina y se produce". La propuesta de incorporar las prácticas alternativas aquí mencionadas a la búsqueda de economías urbanas plurales e innovadoras pretende tender un nexo de unión entre temáticas poco conectadas hasta el momento, en el contexto de una investigación geográfica que sea económica en los conceptos, contenidos y argumentos teóricos que utiliza, al tiempo que socialmente comprometida en sus fines y en las temáticas planteadas.

\section{REFERENCIAS}

ABREU, M. et al. Absortive capacity and regional patterns of innovation. Londres: Department for Innovation, Universities \& Skills, 2008. Disponible en: <http://www.ekf.vsb.cz/export/sites/ekf/projekty/cs/weby/esf-0116/databaze-prispevku/ clanky_ERSA_2008/1113.pdf>.

ALBERTOS, J.M.; SÁNCHEZ HERNÁNDEZ, J.L. (Cords.). Geografía de la crisis económica en España. Valencia: Publicacions de la Universitat de València, 2014.

AMIN, A.; ROBERTS, J. Knowing in action: beyond communities of practice. Research Policy, n. 37, p. 353-369, 2008.

ASHEIM, B.; BOSCHMA, R.; COOKE, P. Constructing regional advantage: platform policies based on related variety and differentiated knowledge bases. Regional Studies, v. 45, n.7, p. 893-904, 2011.

ASKUNZE, C. Más allá del capitalismo: alternativas desde la Economía Solidaria.

Documentación Social, n. 168, p. 97-116, 2013.

AYDALOT, P. (Ed.) Milieux innovateurs en Europe. París: GREMI.

BALLAND, P.; BOSCHMA, R.; FRENKEN, K. Proximity and innovation: from statics to dynamics. Regional Studies, v. 49, n. 6, p. 907-920, 2015.

BATHELT, H.; GLÜCKLER, J. Toward a relational economic geography. Journal of Economic Geography, v. 3, n. 2, p. 117-144, 2003.

BATHELT, H.; MASKELL, A.; MALMBERG, P. Cluster and knowledge: local buzz, global pipelines and the process of knowledge creation. Danish Research Unit for Industrial 
Dynamics (DRUID) Working Papers, n. 2-12, 2004. Disponible en: <http://www3.druid.dk/wp/20020012.pdf>

BAUWENS, M. edit. Synthetic overview of the collaborative economy. P2P Foundation, 2012. Disponible en: <http://p2p.coop/files/reports/collaborative-economy-2012.pdf>

BECATTINI, G. Dal settore industriale al distretto industriale. Rivista di Economia e Politica Industriale, v. 7, n. 1, p. 7-21, 1979.

BOSCHMA, R. Proximity and innovation: a critical assessment. Regional Studies, n. 391, p. 61-74, 2005.

CASTELLS, M. La ciudad informacional. Tecnologías de la información, reestructuración económica y el proceso urbano-regional. Madrid: Alianza Editorial, 1995.

CASTELLS, M.; HALL, P. Las tecnópolis del mundo. la formación de los complejos industriales del siglo XXI. Madrid: Alianza Editorial, 1994.

COMISIÓN EUROPEA. Libro verde de la innovación. Bruselas: Comisión Europea, 1995.

COMISIÓN EUROPEA. Europa 2020. Una estrategia de crecimiento inteligente, sostenible e integrador. Bruselas: Comisión Europea, 2010.

CONILL, J. et al. Otra vida es posible. Prácticas económicas alternativas durante la crisis. Barcelona: UOC Ediciones, 2012.

COOKE, P. Regional innovation systems and the knowledge economy. Industrial and Corporate Change, v. 10, n. 4, p. 945-974, 2001.

COOKE, P.; LAZZERETTI, L. (eds.). Creative cities, cultural clusters and local economic development. Cheltenham: Edward Elgar, 2008.

CORTI, M. De la resistencia a la acción. En: M. BELIL, J. BORJA; M. CORTI (Eds.). Ciudades, una ecuación imposible. Barcelona: Icaria, 2012, p. 23-27.

DALLABRIDA, V. R.; FERNÁNDEZ, V. R. Desenvolvimento territorial: possibilidades e desafios, considerando a realidade de âmbitos espaciais periféricos. Passo Fundo: Editora UPF/Ijuí: Editora UNIJUI, 2008.

DCMS. Creative industries mapping document. Londres: Department for Culture, Media and Sport, 1998.

DESFORGES, M.; GILLI, F.; CORDOBA, V. Territoires et innovation. París: DATAR-La Documentation Française, 2013.

DÍAZ DE SARRALDE, S.; ESTRADA, B. Otro modelo económico y social para España. Una propuesta progresista para salir de la crisis. Madrid: Fundación $1^{\circ}$ de MayoFundación Alternativas-Fundación Largo Caballero, 2015. Disponible en: <http://www.1mayo.ccoo.es/ nova/files/1018/ LibroOtroModelo.pdf>

DOSI, G. et al. Technical change and economic theory. Londres: Pinter Publishers, 1988.

DRd - Desenvolvimento Regional em debate (ISSNe 2237-9029) 
ETXEZARRETA, M. Reflexionando sobre las alternativas. Dossieres EsF, 13, p. 11-14, 2014.

ETXEZARRETA, E. et al. Innovación social, políticas públicas y economía social y solidaria. Papeles de Economía Solidaria, REAS Euskadi, n. 5, 2015. Disponible en: <http:// www.economiasolidaria.org/papeles_ES_5>

ETZKOWITZ, H.; LEYDESDORFF, L. Universities in the global economy: a triple-helix of university-industry-government relations. Londres: Cassell Academic, 1997.

FEDEA. Una agenda de crecimiento para España. Madrid: Fedea-McKinsey\&Company, 2010.

FELT, U. et al. Taking European knowledge society seriously. Bruselas: Comisión Europea, 2007.

FLORIDA, R. The rise of the creative class and how it's transforming work, leisure, community and everyday life. Nueva York: Basic Books, 2002.

FLORIDA, R. Towards the learning region. Futures, n. 5, p. 527-536, 1995. Disponible en: <http://www.creativeclass.com/rfcgdb/articles/1995-FuturesTowardtheLearningRegion.pdf>

FLØYSAND, A.; JAKOBSEN, S.E. The complexity of innovation: a relational turn. Progress in Human Geography, v. 35, n. 3, p. 328-344, 2010.

FONTAN, M.; KLEIN, J.L.; TREMBLAY, D.G. Innovation et société: pour élargir l'analyse des effets territoriaux de l'innovation. Géographie, Économie, Société, n. 6, p. 115-128, 2004.

FREEMAN, C. The economics of industrial innovation. Harmondworsth: Penguin Books, 1974.

FUNDACIÓN IDEAS. Ideas para una nueva economía. Hacia una España más sostenible en 2025. Madrid, Fundación Ideas, 2010. Disponible en: <http://dialnet.unirioja.es/servlet/ libro? codigo $=572599>$

FUNDACIÓN $1^{\circ}$ DE MAYO; FUNDACIÓN LARGO CABALLERO. El cambio de modelo productivo que España requiere para salir de la crisis. Madrid: Fundaciones $1^{\circ}$ de Mayo y Largo Caballero, 2011. Disponible en: <http://www.1mayo.ccoo.es/nova/files/ 1018/ModeloProductivo.pdf>

GIBSON-GRAHAM, J.-K. Diverse economies: performative practices for other worlds. Progress in Human Geography, v. 32, n. 5, p. 613-632, 2008.

GLAESER, E. El triunfo de las ciudades. Madrid: Taurus, 2011.

GURIDI, L.; PÉREZ DE MENDIGUREN, J.C. La dimensión económica del Desarrollo Humano Local: la economía social y solidaria. Bilbao: Universidad del País Vasco-Hegoa, 2014.

DRd - Desenvolvimento Regional em debate (ISSNe 2237-9029) 
HALL, P.; PRESTON, P. La ola portadora. Nuevas tecnologías de la información y geografía de las innovaciones, 1846-2003. Madrid: FUNDESCO, 1990.

HOWELLS, J.; BESSANT, J. Introduction. Innovation and economic geography: a review and analysis. Journal of Economic Geography, n. 12, p. 929-942, 2012.

JIMÉNEZ HERRERO, L.M. La sostenibilidad como oportunidad ante la crisis: economia verde y empleo. Ambienta, n. 101, p. 42-53, 2012. Disponible en: <http:// www.revistaambienta.es/WebAmbienta/marm/Dinamicas/secciones/articulos/LJH.htm>

KLEIN, J.L.; HARRISON, D. (Ed.). L'innovation sociale. Émergence et effets sur la transformation des societés. Montreal: Presses de l'Université du Québec, 2007.

KLEIN, J.L.; ROY, M. Pour une nouvelle mondialisation. Le défi d'innover. Montreal: Presses de l’Université du Québec, 2013.

KOMNINOS N. Intelligent cities: Innovation, knowledge systems and digital spaces. Londres: Taylor and Francis, 2002.

LANDRY, C. The creative city: a toolkit for urban innovators. Londres: Earthscan, 2000.

LAVAL, C.; DARDOT, P. La nueva razón del mundo. Ensayo sobre la sociedad neoliberal. Barcelona: Gedisa, 2013.

LAVILLE, J.L. Asociarse para el bien común. Tercer Sector, economía social y economía solidaria. Barcelona: Icaria, 2015.

LAVILLE, J.L. L'économie sociale et solidaire, l'entrepreneuriat social et l'innovation sociale. Une mise en perspective historique. En: KLEIN, J.L. et al. (Dirs.). La transformation sociale par l'innovation sociale. Montreal: Presses Universitaires du Québec, 2016, p. 13-20.

LÉVESQUE, B. Innovations sociales et pouvoirs publics: ver un système québécois d'innovation dédiée à l'économie sociale et solidaire. Quelques éléments de problématique. Les Cahiers du Crises. Collection Études Théoriques, n. 1106, 2011. Disponible en: <https://crises.uqam.ca/upload/files/publications/etudes-theoriques/ CRISES_ET1106.pdf>

LEYSHON, A.; LEE, R.; WILLIAMS, C. (Ed.) Alternative economic spaces. Londres: Sage, 2003.

LORTHIOIS, J. Économie solidaire, oui, mais pas sans alternative. Mouvements, n. 21-22, p. 213-218, 2002.

LUNDVALL, B.A. (Ed.). National systems of innovation: towards a theory of innovation and interactive learning. Londres: Pinter Publishers, 1992.

LLOBERA, F. Transiciones ecológicas y desarrollo local. En: Retos y futuro del desarrollo económico local. Madrid: Red de Entidades para el Desarrollo Local (REDEL), 2013. p. 171183

DRd - Desenvolvimento Regional em debate (ISSNe 2237-9029) 
MAILLAT, D.; QUÉVIT, M.; SENN, L. Réseaux d'innovation et milieux innovateurs: un pari pour le développement regional. Neuchâtel: EDES, 1993.

MASSEY, D. Londres, diciembre de 2011. En: ALBET, A.; BENACH, N. (Ed.). Doreen Massey. Un sentido global del lugar. Barcelona: Icaria, 2012. p. 247-264.

MÉNDEZ, R. Innovación y desarrollo territorial: algunos debates teóricos recientes. EURE. Revista Latinoamericana de Estudios Urbanos y Regionales, v. 28, n. 84, p. 63-83, 2002.

MÉNDEZ, R. Estrategias de innovación para el desarrollo y la resiliencia de ciudades medias. Documents d'Analisi Geografica, v. 59, n. 3, p. 481-499, 2013.

MÉNDEZ, R. Redes de colaboración y economía alternativa para la resiliencia urbana: una agenda de investigación. Biblio3W. Revista Bibliográfica de Geografía y Ciencias Sociales, 25 nov. 2015. Disponible en: 〈http://www.ub.edu/geocrit/b3w-1139.pdf>

MÉNDEZ, R.; ABAD, L.D.; ECHAVES, C. Atlas de la crisis. Impactos socioeconómicos y territorios vulnerables en España. Valencia: Tirant lo Blanch, 2015.

MOULAERT, F.; SEKIA, F. Territorial innovation models: a critical survey. Regional Studies, v. 37, n. 3, p. 289-302, 2003.

MOULAERT, F. et al. Toward alternative model(s) of local innovation. Urban Studies, v. 42, n. 11, p. 1969-1990, 2005b.

NESTA. Hidden innovation. How innovation happens in six low innovation sectors. Londres: National Endowment for Science, Technology and the Arts, 2007.

OUGHTON, C.; LANDABASO, M.; MORGAN, K. The regional innovation paradox: innovation policy and industrial policy. Journal of Technology Transfer, n. 27, p. 97-110, 2002.

PAZOS, M.; MEDIALDEA, B. Reorganizar el sistema de cuidados: condición necesaria para la recuperación económica y el avance democrático. Madrid: Podemos, 2015. Disponible en: <http://www.trasversales.net/ mpbm.pdf>

PERARD, P. Les clusters d'innovation sociale. Analyse et bonnes pratiques européennes. Pour la Solidarité. Notes d'Analyse, jun. 2015. Disponible en:

<http://www.pourlasolidarite.eu/sites/default/files/publications/files/na-2015-clusters-is.pdf>

PORTER, M. La ventaja competitiva de las naciones. Barcelona: Plaza \& Janés, 1991.

PSARIKIDOU, K. Rethinking innovation through a moral economy lens: the case of alternative agro-food and mobility practices. Ephemera. Theory \& Politics in Organization, v. 15, n. 1, p. 67-93, 2015.

SÁNCHEZ MORAL, S. Territorio, transformación productiva, equidad y redes. Revista de Estudios Andaluces, n. 32, p. 49-75, 2015.

SCOTT, A.J. Human capital resources and requirements across the metropolitan hierarchy of the USA. Journal of Economic Geography, n. 9, p. 207-226, 2009. 
SUBIRATS, J. Introducción. En SUBIRATS, J.; GARCIA BERNARDOS, A. (eds.).

Innovación social y políticas urbanas en España. Experiencias significativas en las grandes ciudades. Barcelona: Icaria, 2015, p. 7-12.

VALE, M. Conhecimento, inovação e território. Finisterra, v. 44, n. 88, p. 9-22, 2009.

VAN DER PANNE, G. Agglomeration externalities: Marshall versus Jacobs. Journal of Evolutionary Economics, n. 14, p. 593-604, 2004.

VAN WINDEN, W.; VAN DEN BERG, L.; POL, P. European cities in the knowledge economy: towards a tipology. Urban Studies, v. 44, n. 3, p. 525-549, 2007.

VON HIPPEL, E. Democratizing innovation. Cambridge MA: The MIT Press, 2005.

WENGER, E. C.; SNYDER, W. M. Communities of practice: the organizational frontier. Harvard Business Review, n. 1, p. 139-145, 2000.

Artigo recebido em: 07/10/2016

Artigo aprovado em: 19/10/2016 